\title{
Advancing research in primary care: A graduate program in family medicine
}

\section{Maedeh Khayyat Kholghi and Gillian Bartlett}

\section{McGill University}

\section{Research in Family Medicine}

Family physicians are responsible for delivering effective, patient-centered and equitable care to patients by addressing prevention, management and treatment of health conditions. ${ }^{1}$ The broad spectrum of biological, psychological, social, ethical and spiritual issues targeted by family medicine makes primary care an astonishing and complex field.

Primary care research has been suggested as a critical component in the development of high quality evidencebased health care. ${ }^{2}$ It is known that family medicine research strengthens the knowledge base in primary care, and contributes to the improvement of the health care system, as well as the betterment of medical care. ${ }^{3}$ Nevertheless, the advancement of research in primary care and family medicine has been a slow process, possibly due to limited resources, insufficient research training, and lack of interest by family physicians in conducting research. ${ }^{4}$

For research to have a direct impact on the practice of family medicine, the leadership of family physicians with both practice and research skills is crucial. ${ }^{3}$ In order to promote research advancement in family medicine and engage family physicians in conducting research, there is a need to develop training programs specialized in family medicine research.

\section{Masters in Family Medicine}

To address some of the training needs required to conduct rigorous research in family medicine, a research-oriented thesis-based Masters (MSc) program in family medicine has been established at McGill University. Their mission is to advance the field of family medicine through the production of new knowledge, and to provide the evidence necessary to underpin high quality clinical care in family practice. ${ }^{6}$ This program is one of the few of its kind in North America that is designed specifically to improve the skills necessary to carry out research pertinent to the practice of family medicine. ${ }^{5}$ On average approximately 10 students are enrolled per year, and these candidates include practicing family physicians, residents, medical graduates, and undergraduate university students with a strong interest in family medicine. Courses on different research approaches and methodologies are offered during the first year of training. In the second year, the focus is primarily on conducting a research project and writing a thesis. Research projects are clinically based and/or address issues pertinent to non-clinical aspects of primary care including primary prevention programs. Studies take place at family medicine sites and family physicians are either the lead or heavily involved in projects. Upon graduation, candidates can pursue careers as clinician scientists, family medicine research managers, or further their graduate training with a PhD in Family Medicine.

\section{Specifications of the Graduate Program}

In 2004, the World Organization of Family Doctors (WONCA) published a set of recommendations to address the gap in family medicine research. ${ }^{1}$ The MSc program at McGill has addressed these recommendations, some of which are described below.

\section{Interdisciplinary}

Research in family medicine, apart from covering issues related to best practices and clinical uncertainties, also includes the broader context of patient care, the biopsychosocial reality of patients, and the socioeconomic and cultural determinants of health. ${ }^{1,7,8}$ The interdisciplinary nature of family medicine requires understanding of various disciplines and research methodologies. The MSc program recognizes the importance of crossing conventional 
boundaries of disciplines and provides training in epidemiology, statistics, health policy, sociology, and ethnography. It also focuses on teaching different types of research methodologies including qualitative, quantitative, and mixed methods.

\section{Participatory Approach}

Participatory action research is defined as a systematic investigation with the collaboration of communities affected by the issues under study, for the purpose of taking action and implementing social change. ${ }^{9}$ This approach has been recommended as an effective way to engage family physicians directly in the research needs of their community. ${ }^{9}$ Participatory Research At McGill (PRAM), in partnership with the MSc program, offers courses and monthly seminars on participatory action research and its impact, as to encourage adoption of this approach for addressing important health issues.

\section{Dissemination}

An essential aspect of capacity building is to transfer knowledge and share information on a wider platform. ${ }^{10}$
Participating in primary care conferences allows family physicians to freely exchange ideas, adapt new research findings, and discuss questions and challenges encountered in family medicine. The MSc program strongly encourages its candidates to showcase their research projects at international and national primary care conferences; this provides a basis for improving the relationship between family medicine researchers and the wider scientific community. It further offers evidence-based knowledge to physicians, which will ultimately improve family medicine practice.

\section{Conclusion}

Addressing research questions pertinent to clinical practice is necessary to improve patient care. In order to increase recognition of value in primary care research among primary care physicians, there is a need for researchtraining programs focused specifically on family medicine. The McGill graduate research program in family medicine is an excellent model that links the gap between research development and clinical practice, builds capacity for family physicians, and prepares clinical scientists to conduct rigorous research in the discipline of family medicine.

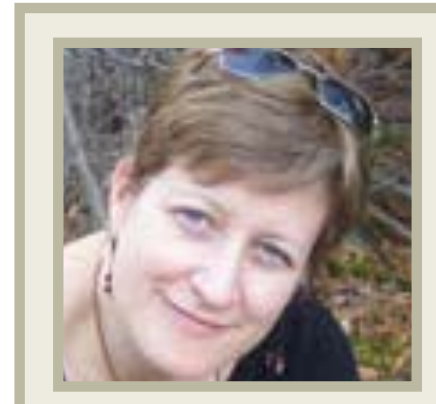

\section{Gillian Bartlett}

Gillian Bartlett, PhD, is the Research Director of the Department of Family Medicine at McGill University. Dr. Bartlett specializes in optimizing quality and safety of patient care. Her research involves health informatics, pharmacoepidemiology, population health and evaluation methodologies for complex data sets in primary care. Her current focus is on the role of health informatics, knowledge translation and genomic medicine on patient safety in family medicine.

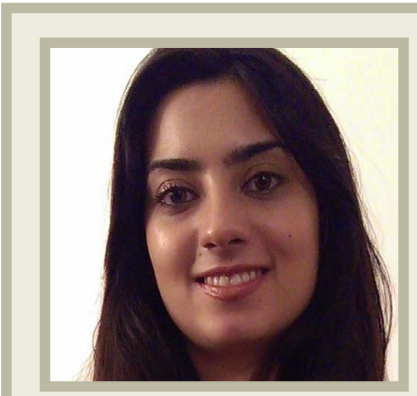

\section{Maedeh Khayyat Kholghi}

Maedeh Khayyat Kholghi completed her MSc degree in Family Medicine from McGill University. Her research was focused on evaluating a diabetes prevention program in an Aboriginal Community. She explored the barriers and facilitators of this program using a community-based participatory research approach. Maedeh also holds a BSc in Physiology from McGill University and will be pursuing her medical degree at Marian University in Indianapolis in the hopes of becoming a clinician scholar. 


\section{References}

1. Van Weel C, Rosser WW. Improving health care globally: A critical review of the necessity of family medicine research and recommendations to build research capacity. Ann Fam Med. 2004; 2(2): S5-S16.

2. Rosser WW, Van Weel C. Research in family/general practice is essential for improving health globally. Ann Fam Med.2004; 2(2):S2-S4.

3. Van Weel $\mathrm{C}$. The impact of research in primary care and family medicine: the Thomson Reuters Web of Science Subject Category 'Primary Health Care'. Fam Pract. 2011; 28 (3): 239-40.

4. Askew DA, Glasziou PP, Del Mar CB. Research output of Australian general practice: A comparison with medicine, surgery and public health. Med J Aust. 2001; 175(2): 77-80.

5. Bartlett $G$, Rodriguez C, Boillat $M$. Encompassing research plurality: A family medicine graduate programme. Med Educ.2012; 46(11): 1115-6.

6. Graduate Programs. McGill University: Family Medicine; 2014 [Cited 2014 January 30] Available from: http://www.mcgill.ca/familymed/research$\mathrm{grad} /$ graduate-programs.

7. De Maeseneer JM, Van Driel ML, Green LA, Van Weel C. The need for research in primary care. Lancet. 2003; 362(9392): 1314-9.

8. Van Weel C. Examination of context of medicine. Lancet. 2001; 357(9258): 733-4.

9. Macaulay AC, Commanda LE, Freeman WL, Gibson N, McCabe ML, Robbins $\mathrm{CM}$, et al. Participatory research maximises community and lay involvement. BMJ.1999; 319(7212): 774-8.

10. Hay AD, Rortveit $G$, Purdy S, Adams J, Sanci LA, Schermer TR et al. Primary care research-an international responsibility. Fam Pract. 2012; 29(5): 499-500. 